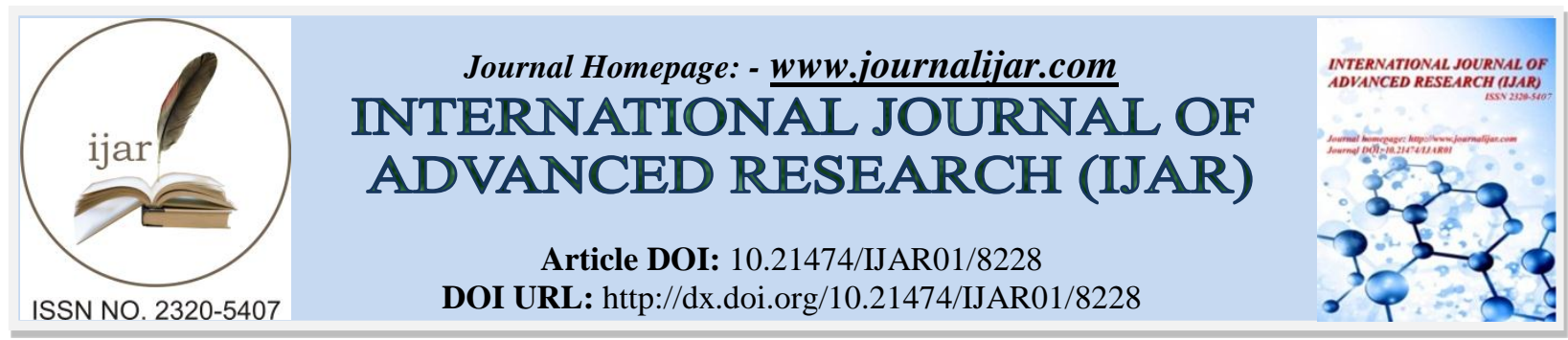

RESEARCH ARTICLE

\title{
INFLUENCE OF SKY YOGA, SURIYANAMASKARAM AND ASANAS ON MENTAL STRENGTH OF GIRLS.
}

1. PhD Scholar, Bharathiar University.

\section{S. Chellappa ${ }^{1}$ and S. Prasath ${ }^{2}$.}

2. Asst. Professor, Department of Yoga for Human Excellence WCSC Vision, SKY Research Centre, Aliyar Pollachi - 642102.

\section{Manuscript Info}

\section{Manuscript History}

Received: 18 October 2018

Final Accepted: 20 November 2018

Published: December 2018

\section{Keywords:}

sky yoga, Suriyanamaskaram, selfefficacy, mental strength.

\begin{abstract}
Purpose:This study was undergone to view the influence of sky yoga and Suriyanamaskaram\& asanas on girls in the modern society which affects them mentally.

Methodology:For the study 45 girl students from Coimbatore were selected as subjects. They age range from 18 to 21 years. The subjects divided into three groups each consisting of 15 members. Experimental Group I went on SKY yoga training only; Experimental Group II went on only Suriyanamaskaram for 12 weeks. Control Group were kept under active rest.

Results:The study shown that there was significant improvement in self-efficacy level of the subjects in the Experimental groups I and II than the Control group.

Conclusion:It has been concluded that SKY yoga improving the mental strength of the girls which helps them to face the modern society boldly and handle the tough situations.
\end{abstract}

Copy Right, IJAR, 2018,. All rights reserved.

\section{Introduction:-}

Yoga is a systematic practice for the realization of higher perceptions. It is the science of life and an ideal way of living, providing rhythm to the body, melody to the mind, harmony to the soul and thereby symphony to life. In short, Yoga is a way to achieve total health, peace, bliss and wisdom. Physical, mental and spiritual aspects of yoga help to make one's life purposeful, useful and noble. Thus Yoga is an art, science and philosophy, which influence the life of man at each level. Therefore, the effect of yoga must be felt in every movement of our day- to- day lives. This demands an almost total relinquishment of interest in other activities of life except the chosen path. The mind is fluid and runs after sensual pleasures. Art demands total undivided focal attention. This demands an almost total relinquishment of interest in other activities of life except the chosen path. The mind is fluid and runs after sensual pleasures. Art demands total undivided focal attention.

\section{Objectives Of The Study}

This study was conducted to view the influence of sky yoga, Suriyanamaskaram\& asanas among college girl students which intently improving their mental strength and health.

\section{Corresponding Author:-S. Chellappa.}

Address:-PhD Scholar. Bharathiar Universitv. 


\section{Statement Of The Problem}

The key to the whole problem is "self-help". First of all, everyday one should learn how to view the problem and face that one. Learning 'how' is the essential one in the once life. The way you organize and run is a kind of socializing, and care taken as per their objectives largely affect the method of handling the problem in the modern world its most needed one for girls since world moves towards curial one. Strength in our mind which will helps every individual to face everything. Yoga is the key which correct them and guide throughout life.

\section{Hypothesis}

There was a significant difference in the Blood Pressure variable in-between sky yoga, Meditation and Kayakalpa than the Control group.

\section{Limitations}

1. Economic status was not considered for the study.

2. The factors of nutrients, heredity, environment, climatic condition etc., were not consider.

3. The heredity problems were not taken into consideration.

4. The food habits, culture, life style, sleep etc., were not controlled.

5. Daily routine works of the students were not taken in to the count.

\section{Selection Of The Subjects}

For the study 45 college girl students from Coimbatore district were selected as subjects. Their age is between 18 to 21 years. The subjects were divided randomly into three groups each consisting of 15 members. Experimental Group I went on SKY yoga training; Experimental Group II went on Suriyanamaskaram\& asanas for 12 weeks for 5 days in a week. Control Group were not given any kind of trainings. The pre and posttest has been taken before and after the training

\section{Independent Variables}

Yoga practices of

1. SKY yoga

2. Suriyanamaskaram\& asanas

\section{Selection of dependent variables: \\ General self-efficacy scale \\ Purpose:}

To scale is a self-report measure of self-efficacy.

\section{Validity:}

The general self-efficacy scale is correlated to emotion, optimism, work satisfaction. Negative coefficients were found for depression, stress, health complaints, burnout, and anxiety.

\section{Scoring:}

1. not at all true

2. hardly true

3. moderately true

4. exactly true

The total score is calculated by finding the sum of the all items. For the GSE, the total score ranges between 10 and 40 , with a higher score indicating more self-efficacy.

\section{Results And Discussion:-}

The data collected from the pre-test and posttest on general self-efficiency of experimental groups and control group have been statistical analysis and presented in Table I.

Table I:-Analysis of Covariance for the pre and post test data on General Self-Efficiency

\begin{tabular}{|c|c|c|c|c|c|c|c|}
\hline TEST & GROUP1 & GROUP2 & GROUP3 & $\mathrm{df}$ & SS & MOS & F value \\
\hline Pre & 23.2 & 23.4 & 24.13 & 2 & 7.24 & 3.62 & $4.9 *$ \\
\hline
\end{tabular}




\begin{tabular}{|c|r|r|r|r|r|r|r|}
\hline & & & & 42 & 745.73 & 17.75 & \\
\hline Post & 34.66 & 28.4 & 26.53 & 2 & 544.53 & 272.26 & \multirow{2}{*}{$22.65^{*}$} \\
\cline { 1 - 4 } & & & & 42 & 504.66 & 12.02 & \\
\hline Adjusted & 34.83 & 28.47 & 26.29 & 2 & 586.73 & 293.36 & \multirow{2}{*}{$33.25^{*}$} \\
& & & & 41 & 361.68 & 8.82 & \\
\hline
\end{tabular}

*Significance at 0.05 level

Table value required for significant at 0.05 level with df 2 and 42 and 2 and 41 are 3.22 and 3.23 respectively.

Table I shows that the adjusted post-test means values of Job involvement for SKY yoga Group, Suriyanamaskaram \& asanas Group and Control Group are 34.83, 28.47 and 26.29 respectively. The obtained F-ratio of 33.25 for adjusted posttest mean is greater than the table value of 3.23 for df 2 and 41 required for significant at .05 level of confidence.

The results of the study indicate that there are significant differences among the adjusted post-test means of SKY yoga Group, Suriyanamaskaram \& asanas Group and Control Group on the general self-efficiency. To determine which of the paired means had a significant difference, the Scheffe's test was applied as Post hoc test and the results are presented in below Table II.

Table II:-Scheffe's test for the differences between the adjusted post-test paired means on General Self-Efficiency

\begin{tabular}{|c|c|c|c|c|}
\hline \multicolumn{3}{|c|}{ Groups } & Mean & \multirow{2}{*}{ CD } \\
\hline Exp Group1 & Exp Group2 & Control Group & & \multirow{2}{*}{5.35} \\
\hline 34.83 & 28.47 & & -6.35 & \\
\hline 34.83 & & 26.29 & -8.54 \\
\hline
\end{tabular}

* Significant at.05 level of confidence

Table II shows the results of the studies are a significant in General Self-Efficiency between the adjusted post-test means of SKY yoga Group and Suriyanamaskaram \& asanas, SKY yoga Group and Control Group, Suriyanamaskaram \& asanas Group and Control Group. However, the improvements of General Self-Efficiency were significantly higher for SKY yoga Group than Walking Practice Group and Control Group.

It shown SKY yoga Group is better than Suriyanamaskaram \& asanas Group and Control Group in improving General Self-Efficiency.

The mean and adjusted values of pre and posttest of SKY yoga Group, Suriyanamaskaram \& asanas Group and Control Group on General Self-Efficiency are graphically represented in the Figure -I.

Figure I:-

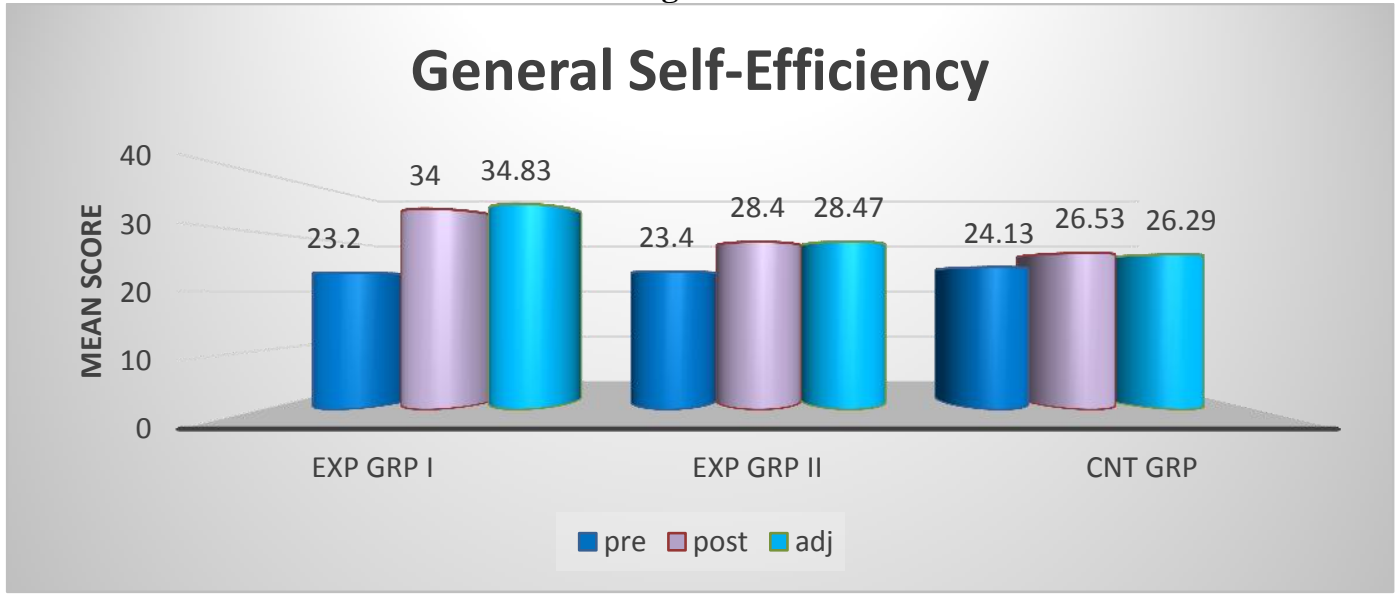




\section{Conclusions:-}

Based on the result of the study the following conclusions were drawn.

1. There was a significant difference between SKY Yoga group and Suriyanamaskaram \& asanas group when compared to the control group on psychological variables of General Self-Efficiency.

2. SKY Yoga was found to be better than the Suriyanamaskaram \& asanas group and control group in psychological variables of General Self-Efficiency.

\section{Recommendations:-}

1. A similar study may be conducted by selecting other psychological variables as criterion variables.

2. A similar study may be conducted by selecting Performance related variables as criterion variables.

3. A similar study may be attempted by selecting other physiological variable for the subjects.

4. A similar study may be conducted for male group as subjects.

5. Similar study may be undertaken to analyze the other physiological and Hematological parameters.

\section{References:-}

1. Li AW, and Goldsmith CA. (2012), "The effects of yoga on anxiety and stress.", Altern Med Rev.;17(1):2135.

2. Shankarapillai R, (2012), "The effect of yoga in stress reduction for dental students performing their first periodontal surgery: A randomized controlled study.”, Int J Yoga. Jan;5(1):48-51

3. Usha Lohan and Dolly Rajesh (2002), "Effect of Asanas and pranayamas on physical and physiological components of boys between age group 12-16 years." Journal of Sports and Sports Sciences 25 (1) 50-56.

4. schwarzer, r., \& Jerusalem, m. (1995). generalized self-efficacy scale. in j. Wineman, s. right, \& m. Johnston, measures in health psychology: a user's portfolio. causal and control beliefs (pp. 35-37). Windsor, uk: nfernelson. 